LAWRENCE LIVERMORE NATIONAL LABORATORY

\title{
Space Debris De-Orbiting by Vaporization Impulse Using Short Pulse Laser
}

J. T. Early, C. Bibeau, and C. Phipps

September 16, 2003

Second International Symposium on Beamed Energy Propulsion, Sendai, Japan, October 20-23, 2003 
This document was prepared as an account of work sponsored by an agency of the United States Government. Neither the United States Government nor the University of California nor any of their employees, makes any warranty, express or implied, or assumes any legal liability or responsibility for the accuracy, completeness, or usefulness of any information, apparatus, product, or process disclosed, or represents that its use would not infringe privately owned rights. Reference herein to any specific commercial product, process, or service by trade name, trademark, manufacturer, or otherwise, does not necessarily constitute or imply its endorsement, recommendation, or favoring by the United States Government or the University of California. The views and opinions of authors expressed herein do not necessarily state or reflect those of the United States Government or the University of California, and shall not be used for advertising or product endorsement purposes. 


\title{
Space debris de-orbiting by vaporization impulse using short pulse laser
}

\author{
James. T. Early*, Camille Bibeau*, Claude Phipps** \\ *Lawrence Livermore National Laboratory, University of California \\ 7000 East Avenue, Livermore CA 94550, USA \\ ** Photonic Associates \\ 200A Ojo de la Vaca Road, Santa Fe, NM 87505, USA
}

\begin{abstract}
Space debris constitutes a significant hazard to low earth orbit satellites and particularly to manned spacecraft. A quite small velocity decrease from vaporization impulses is enough to lower the perigee of the debris sufficiently for atmospheric drag to de-orbit the debris. A short pulse (picosecond) laser version of the Orion concept can accomplish this task in several years of operation. The "Mercury" short pulse Yb:S-FAP laser being developed at LLNL for laser fusion is appropriate for this task.
\end{abstract}

\section{SPACE DEBRIS PROBLEM}

Forty years of space activity have produced over one hundred thousand pieces of space debris larger than $1 \mathrm{~cm}$ in near-Earth orbits. In the frame of a low-Earth orbit (LEO) satellite, the relative velocity of manmade debris is $10-12 \mathrm{~km} / \mathrm{s}$, depending on orbit inclination. This is because, since the dawn of the Space Age, many satellites have been launched in polar orbits as well as eastward. Debris, arising form explosions and jettisoned objects, take a similar path to that of their source. At such velocity, the damage even very small debris can do is impressive. The debris flux in the $400 \mathrm{~km}$ and $800 \mathrm{~km}$ altitude regions (Fig. 1) has been summarized previously [1]. These altitudes reflect the fluxes seen by the International Space Station, several satellite arrays and by Space Shuttle operations. Space debris in low-Earth orbit threatens any mission in the $1000 \mathrm{~km}$ altitude vicinity which has a product of exposed area and lifetime of the order of $10^{5} \mathrm{~m}^{2}$-yr. For the NASA International Space Station, the chance of significant impact during 10 years is probably $2 \%$.

The space debris hazard to the Space Shuttle is a one-in-two hundred chance of loss of vehicle in each flight $[2,3]$. The primary hazard is damage to the leading edge of a wing leading to an accident similar to the Columbia loss. For some missions the loss of vehicle danger from space debris is greater than the whole accent stage of the flight. To date this risk has been accepted since there has been no economically or technically plausible way to eliminate the debris hazard. Most of the focus has been on minimizing the vulnerability of the Space Shuttle, the International Space Station and other satellites by hardening their designs against impact damage. 


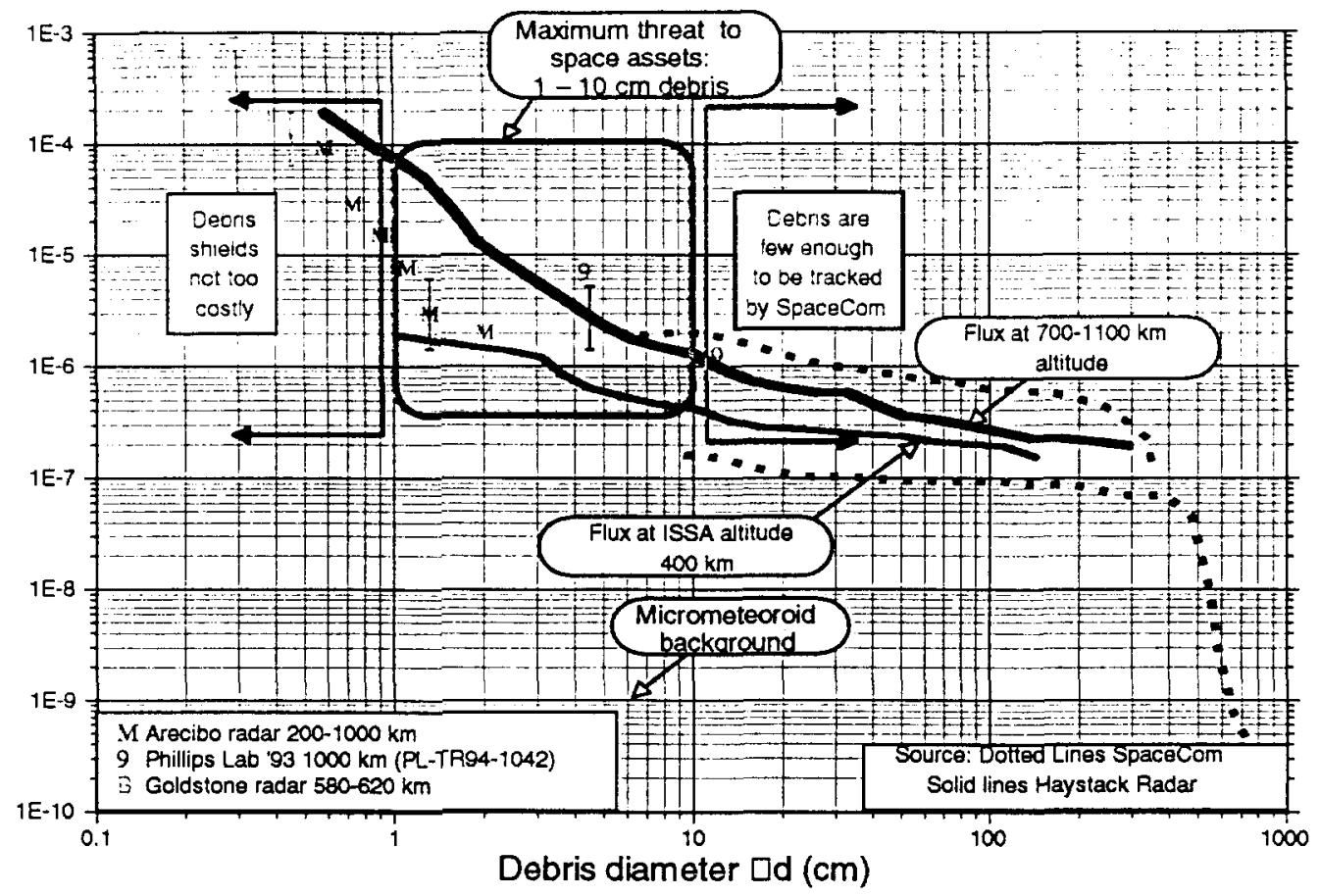

FIGURE 1. The cumulative flux (number $/ \mathrm{m}^{2}-\mathrm{yr}$ ) of space debris larger than a given size for several altitudes and measurement sources.

\section{ORION SPACE DEBRIS CLEARING CONCEPT}

For a review of the ORION concept, the reader is referred to the references $[1,4]$. Briefly, ORION is a ground based laser plus beam director which acquires individual orbiting debris, creates an ablation jet on the surface and, through a combination of retardation and orbit deformation, caused the debris perigee to intersect the Earth's atmosphere. The required velocity change of $100-300 \mathrm{~m} / \mathrm{sec}$ is quite small compared to the orbital velocity. This change can be done efficiently even though, with affordable beam directors, the laser spot size at range in inevitably so large that most of the laser energy goes past the debris. The velocity change is not accomplished in a single pulse, but rather by many minutes of illumination. For much of the debris the velocity change can be accomplished in one orbital pass over the laser facility.

Pulsed laser impulse coupling to the debris targets is characterized by the momentum coupling coefficient $C_{m}$, which is defined as the ratio of target momentum $\mathrm{m} \Delta \mathrm{v}$ produced by photo ablation to incident laser pulse energy $\mathrm{W}$. By convention, this is expressed in mixed units:

$$
\mathrm{C}_{\mathrm{m}}=\mathrm{m} \Delta \mathrm{v} / \mathrm{W} \quad \text { dyne-s/J }
$$

The coupling coefficient will have a maximum $\mathrm{C}_{\text {mopt }}$ because of plasma shielding, inadequate heating and other physics. $\mathrm{C}_{\text {mopt }}$ normally occurs close to the vapor/plasma transition for most of the longer duration pulses. We generally cannot predict the nature of the target material, and the targets are certainly not cooperative. As a simplifying assumption, all materials of which space debris might be composed are 
assumed to have $C_{\text {mopt }}$ values in the range 2-10 dyne-s/J observed with other pulsed lasers. For picosecond class lasers there is a significant amount of data on various materials for the traditional $\mathrm{Q}^{*}$ (laser energy/ material removed) values needed for laser machining, but there have not been many measurements of $C_{m}$.

The fluence needed to achieve $\mathrm{C}_{\text {mopt }}$ is a major design parameter for designing a laser space propulsion system such as ORION. A survey of all reported experiments from which $\mathrm{C}_{\text {mopt }}$ can be deduced was conducted, covering laser wavelength from 248 $\mathrm{nm}$ to $10.6 \mu \mathrm{m}$, pulse durations from $100 \mathrm{ps}$ to $1 \mathrm{~ms}$ and incident fluence from 0.1 to $10^{4} \mathrm{~J} / \mathrm{cm}^{2}$. The surprising result of this survey, reproduced in Figure 2, is that a single trend adequately represents the fluence required to achieve $C_{\text {mopt }}$ over this range. The trend can be described by the simple expression

$$
\Phi_{\mathrm{opt}}=2.4 \times 10^{4} \tau_{\mathrm{p}}^{0.45} \mathrm{~J} / \mathrm{cm}^{2}
$$

The value for the exponent is not surprising, since thermal transient theory for heating a semi-infinite slab to a given temperature (such as boiling temperature) would give exponent of $1 / 2$. The scaling law will breakdown for times shorter than tens of picoseconds because thermal diffusion no longer plays a dominate role. The optimum $\mathrm{Q}^{*}$ and presumably the optimum $\mathrm{C}_{\mathrm{m}}$ then remains approximately constant.

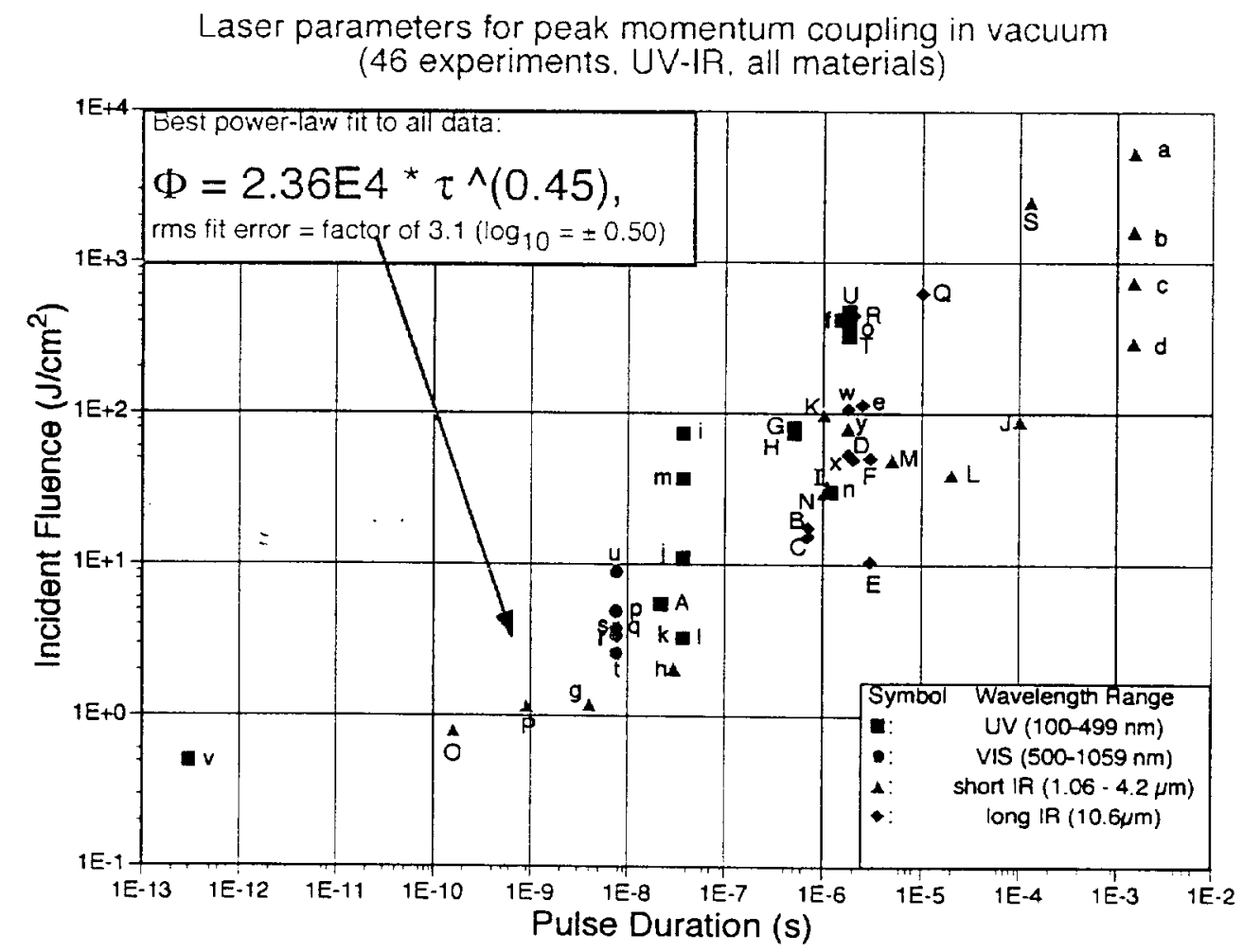

FIGURE 2. Survey of laser parameters for optimum momentum coupling over wide range of wavelengths and pulse duration. The trend line reflects the important role of thermal diffusion. 
Given the diffraction of the laser beam, the pulse energy, W, required to achieve the optimum fluence on a target at range $z$ with a telescope of diameter $D_{b}$ is

$$
W=\Phi_{\text {opt }}\left[4(\lambda z)^{2} / \pi D_{b}^{2}\right] / S T
$$

where $S$ is the Strehl for the beam and $T$ is the transmission of the atmosphere. As expected the required pulse energy decreases with large diameter beam director optics. But the required pulse energy also decreases with pulse duration. This optimum fluence scaling does not continue below several picoseconds; therefore femptosecond lasers should not offer further pulse energy advantages. The corresponding near-field fluence in the atmosphere is

$$
\Phi_{\mathrm{b}}=\left[4 \lambda \mathrm{z} / \pi \mathrm{D}_{\mathrm{b}}^{2}\right]^{2} \Phi_{\mathrm{opt}}
$$

\section{Picosecond Laser Advantages}

It is a fact that it is usually cheaper to get the same laser power from small pulse energy at high repetition rate than the reverse. The target physics outlined above gives smaller pulse energy with shorter pulses. Thus Phipps [5,6] considered using the shortest possible pulses at high repetition rate in the ORION design. Previously only pulses as short as $10 \mathrm{~ns}$ were considered, because this pulsewidth represented the state of well-developed solid state laser technology, and because no coupling data existed around one picosecond. This is still true. Nevertheless, a flood of ablation data [7-16] in the picosecond region has recently appeared which permits us to estimate $\Phi_{\text {opt }}$ in this region. Since the intensity for maximum $C_{m}$ tends to coincide with that for the minimum $Q^{*}$, we can use the $Q^{*}$ values deduced from ablation data to estimate $\Phi_{\text {opt }}$. These values fall near the trend line in Fig.2. The reduced fluence values indicate that ps pulses offer advantages for ORION.

However, we have first to consult the limits set by nonlinear optics in the atmosphere to see what we are permitted to transmit. Eq.4 gives the fluence which must be transmitted through the atmosphere. For ps class lasers the most important mechanism is beam fragmentation due to the non-linear index of refraction and the very high intensity of these very short pulse lasers. The potential for beam fragmentation is usually characterized by the B integral, Eq.5, which must be kept below a value of 3 for stable beams.

$$
\begin{aligned}
& \mathrm{n}=\mathrm{n}_{0}+\mathrm{n}_{2} I \\
& \mathrm{~B}=(2 \pi / \lambda) \mathrm{n}_{2} \mathrm{IL}<3 \\
& \mathrm{n}_{2} \sim 2.5 \times 10^{-19} \mathrm{~cm}^{2} / \mathrm{W}
\end{aligned}
$$

$\mathrm{L}$ is the effective column length of one atmosphere air along the beam. 
Figure 3 shows the design space available for a wide range of laser pulse durations. For the longer, 10ns laser design Stimulated Raman Scattering (SRS) limits atmospheric beam propagation. The limits for air breakdown, Stimulated Thermal Rayleigh Scattering (STRS) and thermal blooming which are not of concern for ps class lasers are also shown. The safe operating region is shown shaded below the solid lines indicating nonlinear process thresholds in the atmosphere.

In the original short pulse ORION (Fig. 3) [5,6] the $140 \mathrm{~J}, 65 \mathrm{~Hz}$ laser had an average power of $10 \mathrm{~kW}$ and pulse lengths of $1 \mathrm{ps}$. While keeping the $10 \mathrm{~kW}$ average power, we will modify the pulse format to $100 \mathrm{~J}, 100 \mathrm{~Hz}$ with 2 ps pulses to match the Mercury laser characteristics. A comparison of the designs is given in Table 1.

The dramatic lowering of pulse energy from the $10 \mathrm{~ns}$ design makes the laser design easier as is reflected by the fact that the low pulse energy technology is currently being demonstrated. The lower (2/3) energy of the Mercury design gives target fluences that are lower than optimum, but still effective. The combination of lower fluence and doubled pulse length gives lower laser intensity in the atmosphere and more margin against beam breakup. The B integral for the Mercury design for a vertical beam is 1 .

The high telescope cost for large values of $D_{b}$ push the designs to as high a value of $\xi$ as achievable within the atmospheric propagation constraints. For ps lasers one is pushed to $10 \mathrm{~m}$ (Keck scale) telescopes.

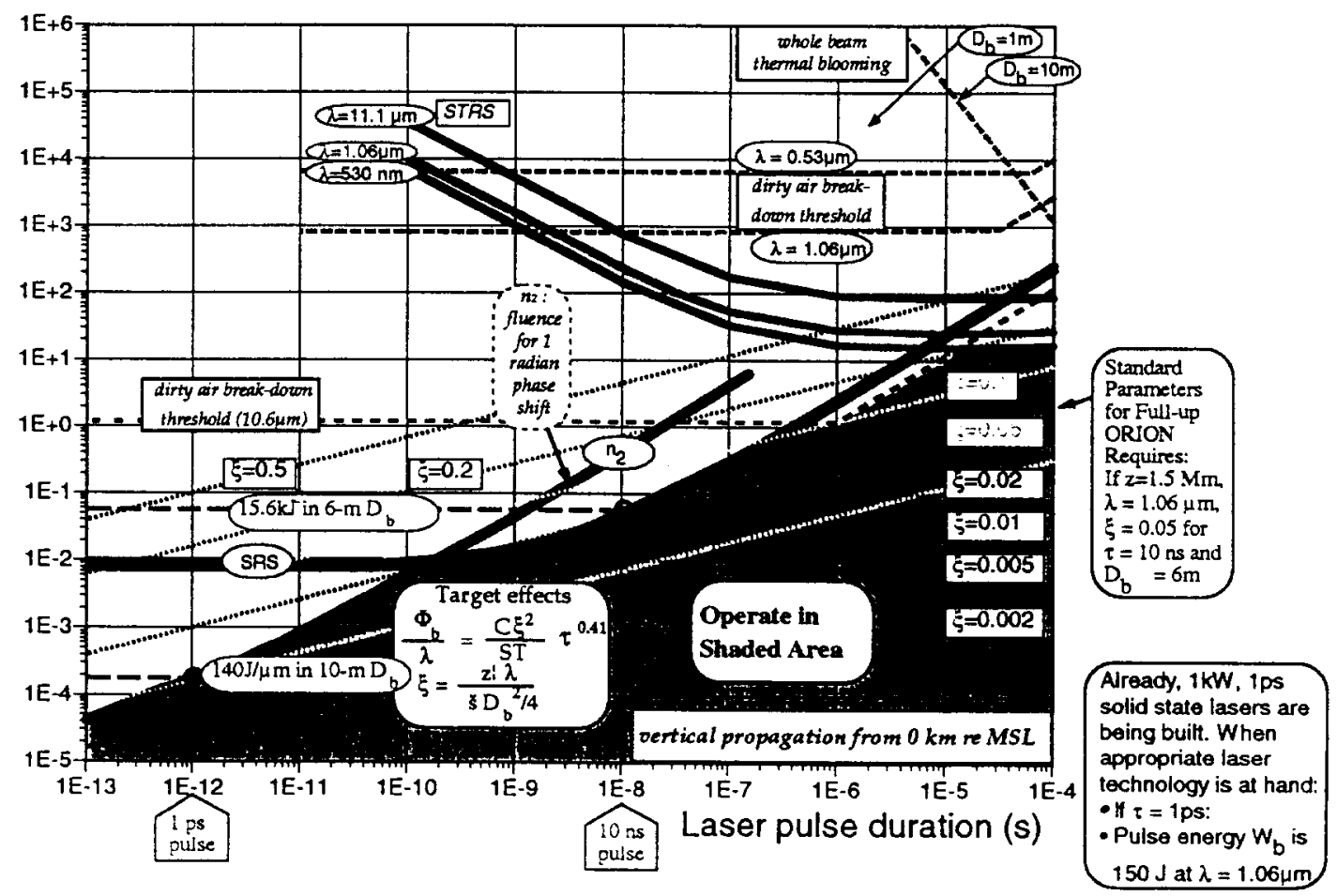

FIGURE 3. "Maneuvering Room Chart" for ORION laser parameters shows the benefits of using ps duration rather than $n s$ duration pulses. The limits for various non-linear effects in the atmosphere are plotted on the chart of near field laser beam values of $\Phi / \lambda$ and laser pulse duration. 
TABLE 1. Comparison of ORION designs for a 10ns and lps options with the Mercury laser based option.

$\begin{array}{llll}\text { System } & \text { Standard 10ns } & \text { Phipps lps } & \text { Mercury based } \\ \text { Laser pulse duration } & 10 \mathrm{~ns} & 1 \mathrm{ps} & 2 \mathrm{ps} \\ \text { Mirror diameter } & 6 \mathrm{~m} & 10 \mathrm{~m} & 10 \mathrm{~m} \\ \text { Laser pulse energy } & 15 \mathrm{~kJ} & 150 \mathrm{~J} & 100 \mathrm{~J} \\ \text { Fluence in atmosphere } & 50 \mathrm{~mJ} / \mathrm{cm}^{2} & 0.2 \mathrm{~mJ} / \mathrm{cm}^{2} & 0.13 \mathrm{~mJ} / \mathrm{cm}^{2} \\ \text { Laser repetition rate } & 2 \mathrm{~Hz} & 65 \mathrm{~Hz} & 100 \mathrm{~Hz} \\ \text { Laser average power } & 30 \mathrm{~kW} & 10 \mathrm{~kW} & 10 \mathrm{~kW} \\ \text { Primary transmission limit } & \text { SRS } & \text { nonlinear refraction } & \text { nonlinear refr. } \\ \text { Required pointing accuracy } & 600 \mathrm{nrad} & 360 \mathrm{nrad} & 360 \mathrm{nrad} \\ \text { Clearing time } & 2 \text { years } & 2 \text { years } & 2 \text { years } \\ \text { Peak target intensity } & 0.5 \mathrm{GW} / \mathrm{cm}^{2} & 200 \mathrm{GW} / \mathrm{cm}^{2} & 70 \mathrm{GW} / \mathrm{cm}^{2} \\ \text { Peak target fluence } & 5 \mathrm{~J} / \mathrm{cm}^{2} & 0.2 \mathrm{~J} / \mathrm{cm}^{2} & 0.07 \mathrm{~J} / \mathrm{cm}^{2}\end{array}$

\section{MERCURY LASER TECHNOLOGY}

A laser system must match the pulse format required to effectively vaporize the space debris while being able to propagate through air as shown in figure 3 . The laser requirements are summarized in Table1. A laser with such a very short pulse duration and modest pulse repetition rate is going to have a very low duty factor. To efficiently energize such a laser one must usually apply the energy over a much longer period than the laser extraction pulse. This requires the use of a "storage laser" material. This type of laser is widely used in laser fusion programs. Generally storage lasers are solid state and when used in a high pulse rate application they are strongly limited by heat removal capabilities. In the Mercury Laser Project LLNL has been developing a solid state Yb:S-FAP laser with diode pump lasers and rapid helium gas cooling to address this issue as part of its Inertial Fusion Energy program. The Mercury laser pulse differs from the required format, and the modifications required to achieve the debris clearing laser requirements are also described below.

\section{Mercury Amplifier}

The heart of the Mercury laser is the power amplifier (Fig. 4) which will operate at $10 \mathrm{~Hz}$ with $100 \mathrm{~J}$ pulses. Ten such lasers would have to be time multiplexed to achieve the $100 \mathrm{~Hz}$ space debris requirement. The Mercury laser utilizes three primary innovations (Fig. 5) to achieve the goal of a high efficiency, high repetition rate laser driver for laser fusion experiments. First the removal of heat from the laser media is accomplished by flowing helium at high speed over the surface of thin laser slabs. The thermal gradients in the laser media are in the short dimension for effective conductive cooling and are in the direction of the laser propagation to minimize the optical distortion. The low index of refraction of helium minimizes the helium thermal-optical distortions that must later be removed with adaptive optics. Figure 4 shows the arrangement of thin laser slabs imbedded in flow vanes within the helium flow duct. Full scale demonstrations have validated the flow and 


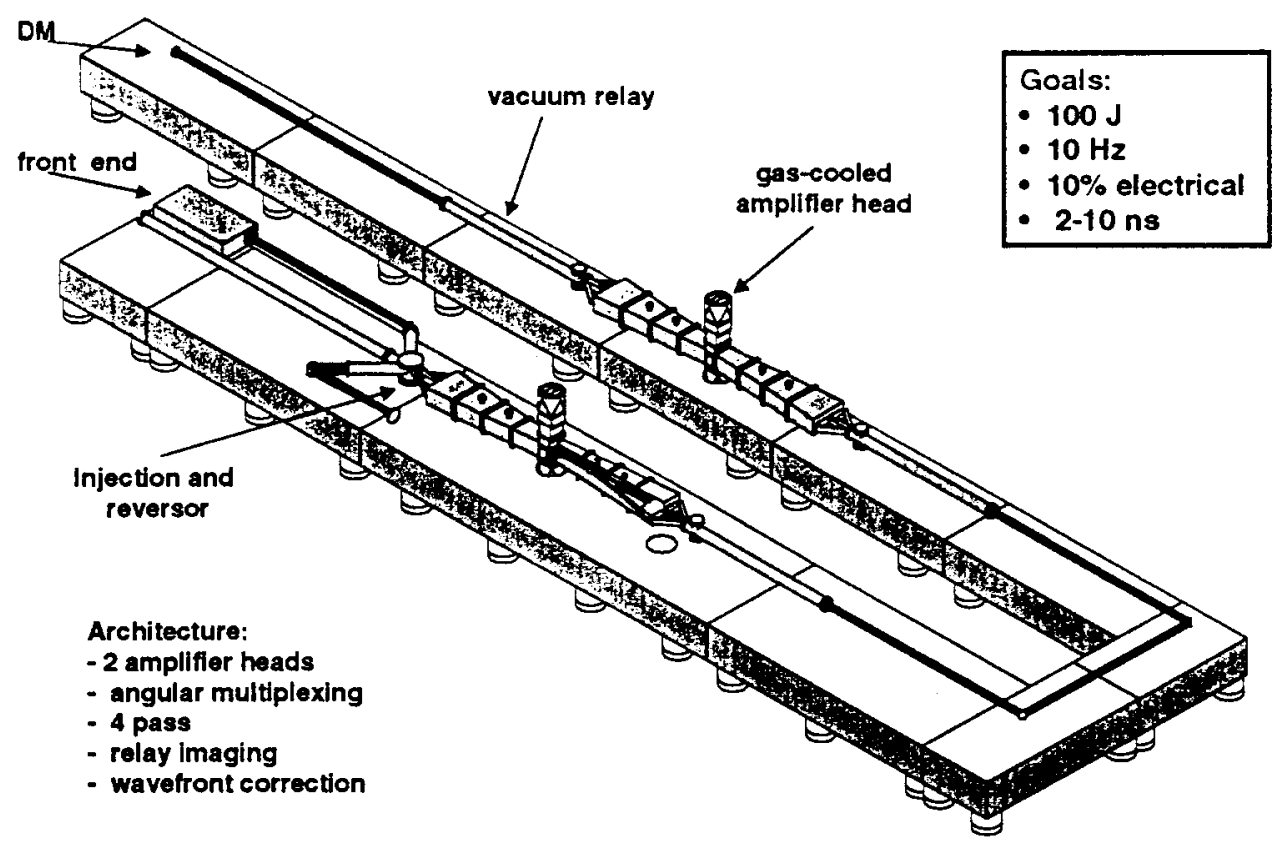

FIGURE 4. The diode-pumped solid state Mercury laser is a high pulse rate, next generation laser fusion driver
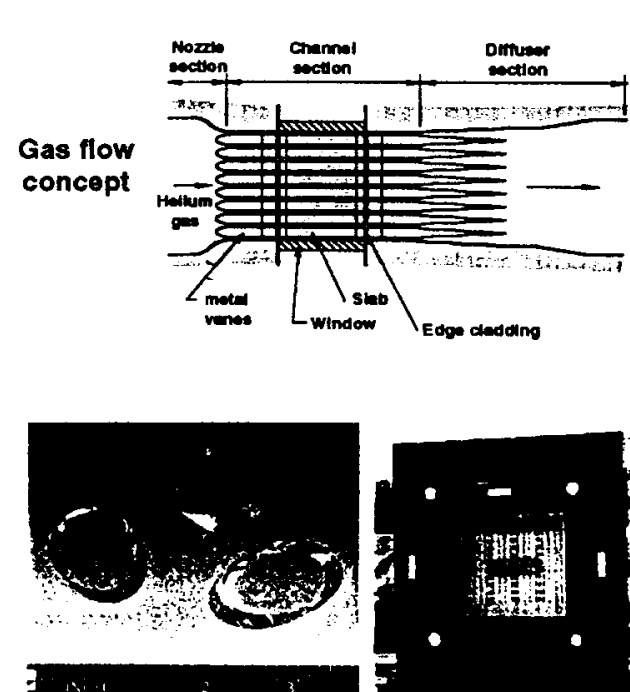

Yb:S-FAP

crystals

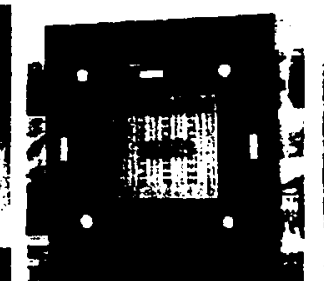

Diode array capable of $160 \mathrm{~kW}$

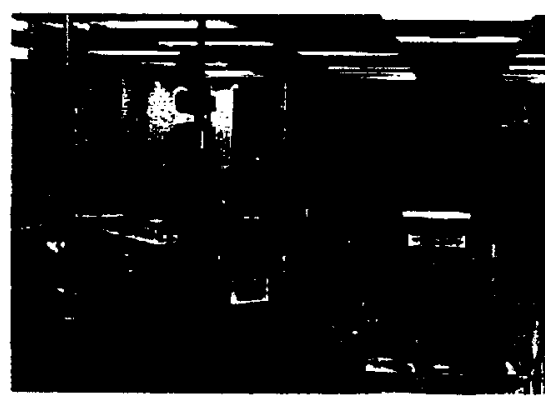

Mercury Lab

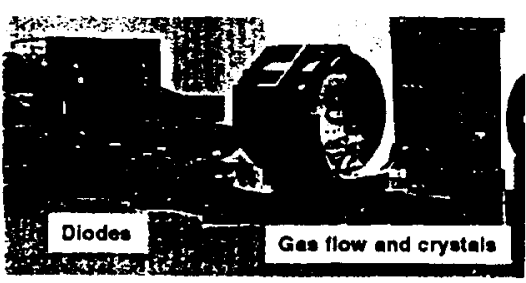

Pump Delivery

FIGURE 5. The Mercury laser will utilize three key technologies: gas cooling, diodes, and Yb:SFAP crystals to deliver $100 \mathrm{~J}$ at $10 \mathrm{~Hz}$ with $10 \%$ efficiency 
thermal models have confirmed that the design meets the optical system requirements.

The second innovation is the use of diode lasers rather than flash lamps to energize the laser media. The narrow frequency output of the diode laser is matched to the absorption band of the laser media. The efficient coupling and the efficiency of diode lasers results in significantly higher pumping efficiency of the laser media and also significantly lowers the waste heat that must be removed by the helium cooling system. The primary challenge for the diode laser design is minimizing the high capital cost of the diode laser and their packaging design. LLNL has developed a low cost packaging design that also efficiently couples the diode light into the laser slabs. This design has been produced under commercial contract and is being tested in the Mercury laser laboratory.

The third innovation is the use of Yb:S-FAP as the laser media instead of the usual Nd-glass. This crystalline media has better thermal conductivity for cooling, longer storage lifetime for efficient pumping, and a high quantum efficiency to minimize waste heat. The growth of these new crystals (Fig. 4) with adequate size and optical quality has been the primary technical challenge in the Mercury project. Crystals grown recently may satisfy these requirements, but some testing remains to be done.

The Mercury laser has two amplifier heads and a four pass optical system. This year one amplifier head and the full optical configuration have been tested in the Mercury laboratory. $30 \mathrm{~J}, 10 \mathrm{~Hz}$ operation has been achieved. Without a second amplifier head the laser fluence is not high enough for efficient power extraction, and $30 \mathrm{~J}$ is the expected performance in this configuration. A second amplifier head is being constructed for full power extraction demonstrations in FY04.

\section{Compressor / Stretcher}

The required debris clearing pulse format cannot be directly achieved by a laser. The combination in the laser pulse of high pulse energy (100J) and a short pulse duration (2ps) generate field intensities that will damage laser materials. This problem is solved by first stretching a very low energy laser pulse to 3 ns and then amplifying this long pulse. The pulse is then compressed back to $2 \mathrm{ps}$. The procedure for stretching and compressing the laser pulse with diffraction gratings known as chirp pulse amplification (CPA) [17] is discussed below. The procedure requires the laser medium to have significant gain bandwidth. The bandwidth $\mathrm{Yb}: \mathrm{S}$ FAP allow pulse compression down to 2 ps.

The basic concept of compressing long pulses into short pulses after amplification is well known and widely used $[18,19]$. The challenge is in designing and fabricating high efficiency gratings that can handle high power laser beams. The specifications for the stretcher and compressor systems are given in Table 2.

The pulses from the oscillator are $2 \mathrm{ps}$ and 1.0nJ. Their transform limited full width half maximum is $0.9 \mathrm{~nm}$. The gratings in the stretcher give the beam an angular spread. The short and long wavelength light follow different length between the optics through the stretcher. The laser pulse has a 3 ns halfwidth 
duration upon exiting. The finite size of the grating results in the truncation of some frequencies and gives the exiting pulse a truncated spectral distribution and a temporal pulse with side lobes. Since the beam in the stretcher is of such low power, there are no technical issues with this system. The system efficiency will be limited by the reflectivity of the gratings in the first order and the frequency clipping due to finite grating size.

The compressor gratings must be designed to handle the full $100 \mathrm{~J}$ pulses without damage. The $100 \mathrm{~Hz}$ pulse rate will also generate an average power thermal concern. The large gold coatings used in laser fusion experiments (Fig. 5) have too large an absorption and would have thermal distortion problems. LLNL has also developed multi-layer dielectric diffraction gratings with high efficiency [20]. Their low absorptivity removes the thermal concerns while also increasing the system efficiency. Figure 6 shows the design of these grating. Alternating layers of hafnia and silica are placed on the substrate to give a high reflectivity, high damage fluence coating. The grating is etched in the silica overcoating. LLNL has recently activated an ion etch facility for fabricating these gratings in sizes up to one by two meters.

TABLE 2. - Specifications for stretcher and compression optical systems

$\begin{array}{lll} & \text { Stretcher } & \text { Compressor } \\ \text { substrate material } & \text { silica } & \text { silica } \\ \text { Coating material } & \text { gold } & \text { Multi-layer } \\ \text { First grating size }(\mathrm{cm}) & 4 \times 15 & 30 \times 84 \\ \text { Second grating size }(\mathrm{cm}) & 4 \times 15 & 30 \times 84 \\ \text { Roof mirror size }(\mathrm{cm}) & 4 \times 8 \text { (flat) } & 30 \times 40 \\ \text { Grating separation }(\mathrm{m}) & 5 & 15 \\ \text { Lines per mm } & 1740 & 1740 \\ \text { Laser beam diameter }(\mathrm{cm}) & 1 & 10 \\ \text { Cut bandwidth }(\mathrm{nm}) & 2.0 & 2.0 \\ \text { Exit sub-pulse duration }(\mathrm{ps}) & 3000 & 2.2 \\ \text { Efficiency-single bounce }(\%) & 90 . & 96.0 \\ \text { System efficiency }(\%) & 60 & 80 \\ \text { Laser macro-pulse fluence }\left(\mathrm{J} / \mathrm{cm}^{2}\right) & 10^{-7} & 1.3 \\ \text { Damage fluence }\left(\mathrm{J} / \mathrm{cm}^{2}\right) & 0.4 & 2.0\end{array}$

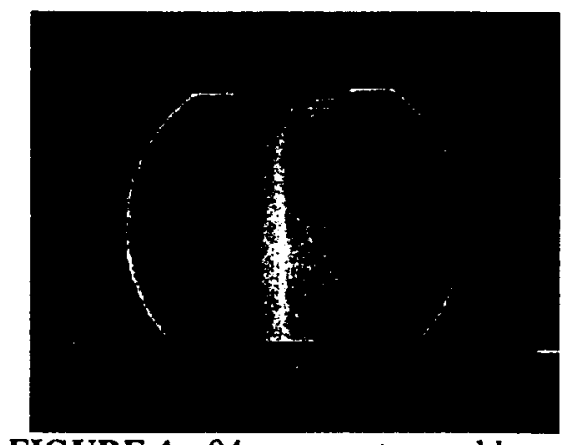

FIGURE 4-94 cm aperature gold coated grating diffraction grating used for pulse compression on the Petawatt laser

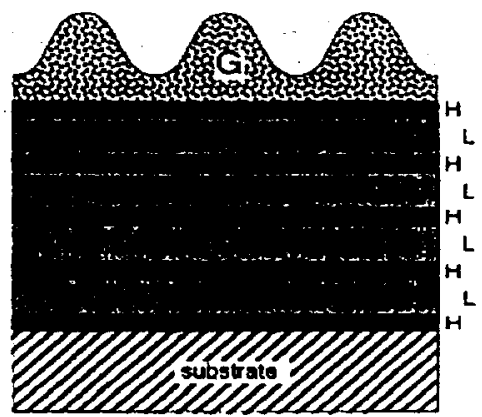

FIGURE. 5 - Multilayer dielectric designs of high-index $(\mathrm{H})$ and low-index $(\mathrm{L})$ layers and groove corrugations (G). Layers form a bigh-reflectivity stack under the corrugations 


\section{Laser System Front End}

The laser system front end must generate a low power laser signal with all the timing and frequency format required to drive the amplifier module. The efficiency of the front end is not particularly important, but it is essential that it produces a high quality controlled signal to be delivered to the Mercury amplifiers.

A laser oscillator will be required with $10 \mathrm{~Hz}$ pulse rate, 2 picosecond pulse duration and pulse energies around 1.0nJ. The laser must be tuned to the $1.047 \mu \mathrm{m}$ wavelength which overlaps the gain bandwidth of the Yb:S-FAP laser amplifiers.

These pulses will then be passed trough an electro-optic modulator that will impose a moderately increasing amplitude ramp on the pulse. This amplitude ramp is designed to offset the decreasing gain ramp that will be experienced in the amplifier as the stored energy is extracted during the laser pulse. The low power $(\sim 1 \mu \mathrm{w})$ is easily handled by current EO modulators.

The gain in the amplifier will have frequency variations across the bandwidth of the laser. To avoid strong amplitude variations at different frequencies in the amplified laser signal, the amplitude of the input laser beam will be sculpted in frequency space [21] to offset the effects of the gain variation. The short pulse length has a frequency bandwidth such that a diffraction grating will spread the beam over a range of angles. In a system produced by XXXXXXXXXXXX the different frequencies are then passed through a programmable liquid crystal display that provides different attenuation for different positions (frequencies) in the beam. The laser beam is next passed through a diffraction grating pulse stretcher, described in a later section, that stretches the 2ps pulses to 3ns. The spectral sculpting and pulse stretching might be combined into a single device if appropriate.

The stretched laser pulses can now be passed through a high gain, low power preamplifier. Two options for the pre-amp have been evaluated; an Optical Pumped Chirped Pulse Amplifier (OPCPA) and a combination of a low power fiber amplifier with a multi-pass Yb:S-FAP pre-amp. An OPCPA operating in the nanosecond pump regime has quite favorable characteristics: a gain of 6-7 orders of magnitude can be readily obtained in a single pass through only $3 \mathrm{~cm}$ of a nonlinear solid-state optical parametric amplifier material (such as $\beta$-barium borate). This can be achieved without bandwidth narrowing at a wide range of center wavelengths and further allows for the broad bandwidth needed for pulse compression. The reduced optical path through the gain medium also results in a reduced B-integral that could otherwise lead to beam breakup instabilities. Other favorable characteristics of OPCPA include a reduction in the level of amplified spontaneous emission by an order of magnitude when compared to a conventional Ti:sapphire amplifier. There is a negligible heat load associated with this perfectly elastic process. A unique characteristic of optical parametric amplification that distinguishes it from amplification in conventional laser gain media is the absence of pump absorption. In this instantaneous nonlinear process unconverted pump energy leaves the amplifier. The disadvantage of this approach is the tight requirements that are placed upon the pump laser and the resulting expense of the pump laser. A pump laser with specifications similar to the Mercury requirements 
has been operated a LLNL. While it may be practical to achieve the technical specifications, the system remains quite expensive and an alternate approach is being explored.

The Mercury program is currently pursing the second option of a low power fiber pre-amp combined with a multi-pass Yb:S-FAP pre-amp. The fiber amplifier has wide bandwidth and stable operation. This technology is quite compact and less expensive. The pre-amp will cause additional gain narrowing so even deeper spectral sculpting will be required to retain the broad bandwidth.

\section{Beam Transport and Multiplexer}

The beams from the ten Mercury lasers operating at ten Hertz must be combined into a single co-aligned beam to produce the required $100 \mathrm{~Hz}$ beam. The beam combination should occur before the pulse compressor to minimize the stress on the combiner optics. At these low pulse rates the simplest beam combination scheme is a simple rotating faceted optic [18].

The combined beam is then transported to the pulse compressor. The pulse compressor can be located in the laser facility or in the beam director telescope facility. The transport of the laser beams will be in vacuum pipes from the exit of the Mercury laser modules. To minimize the evolution of amplitude variations due to diffraction or phase aberrations, the laser beam will be expanded to a nominal ten centimeters and image relayed.

The target tracking system and the beam director telescope are challenging and critical parts of any space debris clearing system. These systems are beyond the scope of this paper which is focusing only on the laser requirements and technology.

\section{DISCUSSION}

When there was no potential method of removing space debris, ton only possible responses from the space community was to harden spacecraft against impacts, minimize the future growth of debris and accept the occational losses. The ORION concept held out a hop for a method to redurce the problem. The demonstrations of the Mercury laser technology by the Inertial Fusion Enery program provides a plausible laser technology. A systems study by NASA isa now neede to gererate a complete and detailed vivion of the integrated system design including evaluations of costs, risks and benefits.

The laser technical risks are dominated by the laser beam quality uncertainties and the lack of prototype demonstrations of some of the subsystems. The Mercury laser being built for the fusion program will serve as the main laser amplifier prototype. This system can easily be modified to demonstrate $2 \mathrm{ps}$ operation. Other critical systems such as the high bandwidth laser system front end will be prototyped.

This proposal focused on the technology currently being demonstrated on Mercury. The Mercury architechture was designed to scale to larger pulse energies 
to meet the fusion program requirements. The debris celearing system may optimize with larger pulse energies and lower repetition rates. The pulse length could probably be increased (easier) to $10-20$ ps to hold down the beam intensity without signigicantly changing the target coupling efficiency. Since it is not clear when the energy scaling of Mercury technology will occu, it is better to focus near term efforts on the demonstrated capabilities.

\section{AKNOWLEDGMENTS}

This work was supported by the U.S. Department of Energy under contract W-7405ENG-48 (UC, LLNL).

\section{REFERENCES}

1. C.R. Phipps, G. Albrecht, H. Friedman, D. Gavel, E.V. George, J. Murray, C. Ho, W. Priedhorsky, M. Michaelis and J. Reilly, Laser and Particle Beams 14 no.1, 1-44 (1966)

2. M.A. Dornheim, "One-I -Two-Hundred Chance". Aviation Week \& Space Technology, pp.30-32, (March 3, 2003)

3. F.H. Hauck (chair), 'Protecting the Space Shuttle from Meteroids and Orbital Debris", 1997 National Research Council report, National Academy Press, (1997)

4. C.R.Phipps, AIP Conference Proceedings 318, Laser Interaction and Related Plasma Pheneomena, $11^{\text {th }}$ International Workshop, Monterey, CA October, 1993; George Miley ed., American Institute of Physecs, New York, pp. 466-8 (1994)

5. C.R. Phipps, "Ultrashort Pulses for Impulse Generation in Laser Propulsion Applications", Thirteenth International Conference on Laser Interactions and Related Plasma Phenomena, AIP Conference Proceedings 406, pp. 477-84 (1997)

6. C.R. Phipps, "Advantages of using ps-pulses in the OPRION Space Debris Clearing System", Proc. International Conference on Lasers 97, STS Press, McLean, VA (1998) pp. 935-941.

7. D.E. Hare, J. Franken, and D.D. Dlott, J. Appl/ Phys. 77, 5950-60 (1995)

8. M. Himmelbauer, E. Arenholz, and D. Bauerle, J. Appl. :hys. A 63, 87-90 (1996)

9. J. Jandeleit, G. Urbasch, H.D. Hoffman, H. Treusch, and E. W. Kreutz, Appl. Phys. A 63, 117-21 (1996)

10. Kautek, et al, "Laser ablation of bielectrics between 20fs and 3ps", Appl. Phys. Lett. 69, 3146-48 (1996)

11. S. Kuper, J. Brannori and K. Brannon, Appl. Phys. A 56, 43-59(1993)

12. S. Nakamura et al., Jpn. J. Appl. Phys. 35, 101-6 (1996)

13. S. Preuss, A. Demchuk, and M. Stuke, "sub-ps UV laser ablation...", Appl. Phys. A 61, 33-7 (1995)

14. B.C. Stuart et. Al., Phys. Rev. 53, 1749-61 (1996)

15. B.C. Stuart et. Al., J. Opt. Soc. Am. B 13, 459-68 (1996)

16. B.C. Suart et. Al., Phys. Rev. Lettl 74, 2248-51 (1995)

17. D.Strickland and G.Mourou, "Compression of amplified chirped optical pulses," Opt. Commun. 56, 219-221 (1985).

18. E.B. Treacy, "Optical pulse compression with diffraction gratings," IEEE J.Quantum Electron. QE5, 454-458 (1969).

19. M.D. Perry and G. Mourou, "Terawatt to petawatt sub-picosecond lasers," Science 264, 917-924 (1994).

20. B.W. Shore, M.D. Perry, J.A. Britten, R.D. Boyd, M.D. Feit, H.T. Nguyen, R. Chow, G.E. Loomis and $\mathrm{Lifeng} \mathrm{Li}$, "Design of high-efficiency dielectric reflection gratings," J.Opt.Soc.Am., 14, No.5, 1124-1136 (May 1997).

21. M.D.Perry, F.G.Patterson, and J.Weston, "Spectral shaping in chirped-pulse amplification," Opt. Lett. 15, 381-383 (1990) 